REVISTA X, Curitiba, volume 14, n.4,p. 120-134, 2019

\title{
A EDUCAÇÃO COMO CUIDADO DE SI: PRÁTICAS DE LIBERDADE DOS CORPOS INFAMES
}

Education as care of the self: practices of liberty of infame bodies

\author{
Bruno FRANCESCHINI (UFCAT) ${ }^{1}$ \\ Antônio FERNANDES JÚNIOR (UFCAT) ${ }^{2}$
}

\begin{abstract}
Resumo: Este artigo tem por objetivo analisar quatro reportagens, retiradas de um portal brasileiro de notícias on-line, em que três travestis doutoras são entrevistadas e tratam de questões relacionadas à obtenção do referido título acadêmico. Dito isso, pretende-se discutir acerca das práticas do cuidado de si por meio da educação pelo sujeito travesti e analisar como, por meio dessas práticas, há a possibilidade de exercício de práticas de liberdade, em um movimento de resistência e transgressão à cisheteronormatividade, que normatiza e normaliza os corpos e as condutas dos sujeitos no que tange às suas práticas de sexualidade. Como arcabouço teórico, esta pesquisa está ancorada nos pressupostos teóricos do pensamento foucaultiano acerca da ética e estética de si e de Pennycook (1996) para a discussão sobre a Linguística Aplicada Transgressiva. Os resultados deste estudo indicam que a transgressão, no funcionamento das relações de poder, é um dos principais elementos para que seja possível o exercício de práticas de liberdade pela travesti e que o cuidado de si, nas práticas educacionais, também opera para que esse corpo resista e seja livre.
\end{abstract}

Palavras-chave: Análise do Discurso; cuidado de si; práticas de liberdade; educação; transgressão.

\begin{abstract}
This article aims to analyze four reports, taken from a Brazilian online news portal, in which three $\mathrm{PhD}$ transvestites are interviewed and deal with issues related to obtaining the referred academic title. Having said that, it is intended to discuss the practices of the care of the self through the transvestite's education and to analyze how, through these practices, there is the possibility of practicing practices of liberty, in a movement of resistance and transgression to cisheteronormativity, that normalizes and normatizes the bodies and behaviors of the subjects related to their practices of sexuality. As a theoretical framework, this research is anchored in the theoretical assumptions of Foucauldian thinking about the ethics and aesthetics of the self and of Pennycook (1996) for the discussion on Transgressive Applied Linguistics. The results of this study indicate that transgression, in the functioning of power relations, is one of the main elements for the practice of practices of liberty by the transvestite and that the care of the self, in educational practices, also operates so that this body could resist and be free.
\end{abstract}

\footnotetext{
${ }^{1}$ Professor Adjunto da Unidade Acadêmica Especial de Letras e Linguística e do Programa de PósGraduação em Estudos da Linguagem da Universidade Federal de Catalão. E-mail: franceschini.bf@gmail.com

${ }^{2}$ Professor Associado da Unidade Acadêmica Especial de Letras e Linguística e do Programa de PósGraduação em Estudos da Linguagem da Universidade Federal de Catalão. E-mail: tonyfer@uol.com.br
} 
REVISTA X, Curitiba, volume 14, n.4,p. 120-134, 2019

Keywords: Discourse Analysis; care of the self; practice of liberty; education; transgression.

\section{INTRODUÇÃO}

A proposta deste texto, pensando com Foucault, é de suscitar a discussão sobre o sujeito travesti, historicamente um corpo abjeto e marginalizado que, pela educação, exerce um cuidado de si e, por consequência, práticas de liberdade de si, resistindo e transgredindo à heterocisnomatividade em nossa sociedade, possibilitando o desenvolvimento e o funcionamento de estratégias de poder para a visibilidade desse corpo.

A escrita sobre esse tema faz-se necessária frente às demandas históricas que exigem respostas, como o pensamento foucaultiano preconiza: quem somos nós hoje? Quem é esse sujeito travesti que resiste? Como resiste? Com relação à historicidade, observamos o aumento de pesquisas sobre as questões de gênero, especialmente sobre o público LGBT+, pesquisas essas que visam abordar tal temática dando respostas, pautadas na ciência em suas diferentes áreas, para questões que procuram dar visibilidade a essa parcela minoritária de nossa sociedade, ainda mais em tempos em que os discursos de ódio têm aumentado, tanto em seu exercício pela violência simbólica quanto pela física.

Dito isso, partindo de uma perspectiva foucaultiana no seio dos estudos do discurso na Linguística e também ancorados na Linguística Aplicada Transgressiva, procuramos discorrer aqui, tendo como corpus quatro reportagens sobre três travestis doutoras, publicadas no portal de notícias G1, do grupo Globo, um dos mais expoentes veículos de comunicação brasileiro.

Na fase de levantamento de dados, constatamos a existência de um total de sete sujeitos transexuais e travestis que obtiveram o grau acadêmico de doutorado nos últimos anos no Brasil, o que é um número extremamente ínfimo, frente aos dados da Plataforma Lattes ${ }^{3}$, onde consta que há 227.41 pessoas com o referido título no país, justificando, portanto, a relevância social para a realização deste breve estudo.

\section{A CONFISSÃO E O CUIDADO DE SI: AS PRÁTICAS DE SUBJETIVAÇÃo, A TRANSGRESSÃO E A CONSTITUIÇÃO IDENTITÁRIA DA TRAVESTI}

\footnotetext{
${ }^{3}$ Disponível em: http://estatico.cnpq.br/painelLattes/. Acesso em 08 de janeiro de 2019.
} 
Partindo do fato de que a sexualidade é o principal tema para a discussão aqui proposta, começamos por problematizar, na esteira do pensamento foucaultiano, a questão da verdade sobre o sexo, uma vez que, ao tratar da sexualidade, Foucault (2010, p. 145) explica: "não é o que se cala, não é o que se é obrigado a calar, mas é o que se é obrigado a revelar.”. Aquilo que se revela está no domínio de uma relação entre o sujeito e a verdade, a verdade de si, tocando, também, em questões do poder e como o sujeito se relaciona nesse meandro entre si, a verdade e o poder, bem como na relação com o outro.

Para este texto, recortamos os enunciados das quatro reportagens ${ }^{4}$ em que há apenas as respostas às questões feitas para as travestis, como uma forma, nesse caso, de se obter uma verdade delas e sobre elas acerca de suas titulações como doutoras e tomamos essas respostas como uma forma de confissão, como uma forma desse sujeito confessar uma verdade sobre seu corpo, que é historicamente interrogado por não atender à norma.

De modo análogo, o corpo da travesti é, para o dispositivo da sexualidade, um corpo monstruoso porque, como explica Foucault (2010), o monstro é o que põe em jogo as esferas médicas e judiciárias. Nesse processo de constituição do corpo monstruoso, há, então, a implementação de um sistema de diferenciação desse corpo, tornando-o anormal e patologizando-o, como materializado nos Manuais Diagnósticos de Saúde Mental (DSM) e no CID-10, sob o código F64, sendo que apenas em 2018 a transexualidade foi retirada do rol de transtornos mentais no DSM-V e ainda mantido no Classificação Internacional de Doenças (CID).

O funcionamento discursivo desses documentos médicos produzem um efeito de verdade sobre o corpo das pessoas transexuais e das travestis, ocasionando um processo de marginalização desses corpos com a defesa de um modo de funcionamento da

4 Disponível em: http://g1.globo.com/ceara/noticia/2012/08/minha-conquista-serve-de-exemplo-diz-1travesti-doutora-do-brasil.html. Acesso em 8 de janeiro de 2019.

Disponível em http:/g1.globo.com/educacao/noticia/2015/01/quero-mostrar-que-e-possivel-diz-travesticotada-reitora-no-ceara.html Acesso em 8 de janeiro de 2019.

Disponível em: https:/g1.globo.com/sp/campinas-regiao/noticia/unicamp-tem-1-travesti-doutora-universidade-aprendeu-ase-transformar-para-que-pessoas-como-eu-caibam-ali.ghtml Acesso em 8 de janeiro de 2019.

Disponível em: https://g1.globo.com/pr/parana/noticia/apos-vida-marcada-por-preconceito-travesti-negraconquista-titulo-de-doutora-na-ufpr.ghtml. Acesso em 8 de janeiro de 2019. 
psiquiatria, num regime de saber poder que visa a "higiene pública da proteção do corpo social" (FOUCAULT, 2010, p. 102).

Embora seja patologizado pelo saber médico, esse sujeito é, de certo modo, porque ainda há muito o que se fazer para essa população, amparado, nos últimos anos, pelo Estado na esfera jurídica, com a promulgação de leis que autorizam a união civil entre pessoas do mesmo sexo, a oferta de procedimento de redesignação pelo Sistema Único de Saúde (SUS), a alteração do nome sem ser necessária a intervenção cirúrgica, bem como a utilização de nome social, dentre outras conquistas.

Assim, por meio das práticas de confissão, procuramos observar e descrever os enunciados, em um primeiro momento, que tratam do modo pelo qual esses sujeitos se vêem enquanto travestis, como elas enunciam uma verdade sobre si, em um jogo de verdade, e como, nesse processo de subjetivação, há a constituição identitária desse sujeito. Portanto, essas questões serão tratadas a partir de três eixos temáticos, a saber, como teoriza Foucault (2014, p. 332): “A partir dos séculos XVI-XVII, estamos em contato com três séries: exclusão-loucura-verdade, correção-prisão-verdade, comportamento sexual-confissão-verdade.”. Para isso, apresentamos a primeira série enunciativa a ser analisada, que trata de como esses sujeitos se constituem, desde a infância:

1) Eu sempre brincava com as meninas, era bem feminina, e os rapazes batiam em mim, reagiam com violência. ${ }^{5}$

2) Eu não sabia como me classificar. Eu não sabia como me definir. Eu só sabia que eu não era um menino. O que definia a minha feminilidade, era o cabelo comprido. Eu tentava deixar crescer, mas a minha mãe não deixava. Então, eu amarrava uma toalha de banho na cabeça e simulava uma peruca. Eu brincava na rua e no quintal de casa com minha peruca improvisada e nunca tive problemas com as outras crianças. $^{6}$

3) Aí começou a complicar mais ainda essa imposição de um gênero masculino. Eu não podia mais usar a minha peruca de toalha, não podia ir pra escola com ela, aliás, eu queria ir, mas a minha mãe não deixava. ${ }^{7}$

Observamos, nestes três enunciados, como, por meio do processo de subjetivação possibilitado pela confissão na entrevista, a constituição identitária do sujeito travesti se dá em questões que transgridem o padrão cisheteronormativo,

\footnotetext{
5 https://glo.bo/1y7Jfqx

6 hitps://glo.bo/2HMdMpf

7 hitps://glo.bo/2HMdMpf
} 
implicando, desse modo, em atos de violência, físicas e simbólicas, contra elas. Nos enunciados em análise, com relação aos traços de feminilidade, destacamos: 1) bem feminina, 2) O que definia a minha feminilidade, era o cabelo comprido e 3) Aí começou a complicar mais ainda essa imposição de um gênero masculino.

No processo de constituição identitária, essas marcas linguísticas produzem efeitos de sentido, como já exposto, de transgressão à cisheteronormatividade. Esses comportamentos transgressivos são observados por questões que tangenciam a feminilidade, ao feminino, como o comportamento, o comprimento do cabelo e a utilização de artifícios materiais que remetem ao que a sociedade estabelece como feminino, no caso, o cabelo longo. Nesse interim, recorremos ao pensamento foucaultiano para discutirmos sobre como, nessas confissões, há a constituição de um sujeito transgressor e violentado desde a infância:

E porque o homem que se rebela é em definitivo sem explicação, é preciso um dilaceramento que interrompa o fio da história e suas longas cadeias de razões, para que um homem possa, 'realmente', preferir o risco da morte à ter certeza de ter de obedecer. (FOUCAULT, 2006, p. 77)

Tendo em vista as considerações foucaultianas e as séries enunciativas, acima citadas, recortamos dos enunciados, os seguintes excertos sobre as práticas de violência: 1) os rapazes batiam em mim, reagiam com violência, 2) Eu tentava deixar crescer, mas a minha mãe não deixava e 3) Eu não podia mais usar a minha peruca de toalha, não podia ir pra escola com ela, aliás, eu queria ir, mas a minha mãe não deixava. A partir desses enunciados, na esteira da discussão sobre a confissão e a transgressão, analisamos que a transgressão é um modo de ser constitutivo da travesti, ao menos nos enunciados em análise, cujos relatos remontam a infância desses sujeitos, pois, sofreram, desde criança, sanções sociais por não poder ter o cabelo longo e estar em um regime de invisibilidade já imposto pela família.

Ao confessarem essas transgressões, observamos como o sujeito travesti, pelo enunciar uma verdade de si, afirma a divisão no interior do discurso sobre a sexualidade, rompendo esse limite, como explica Silva Junior (2018, p. 47): "a sexualidade é fissura e que marca o limite em nós e nos delineia a nós mesmos como limite.”. Analisamos, ainda, essas confissões na entrevista e ao que elas põem em discurso, mobilizando as relações de poder, uma vez que, segundo Foucault $(2018$, p. 8), “a confissão enseja ou reforça uma relação de poder exercido sobre aquele que confessa. Por isso, toda confissão é 'custosa'.”.

Por fim, sobre a questão da confissão, apresentamos a segunda série enunciativa recortada do corpus deste estudo, série essa que apresenta enunciados em uma perspectiva política do sujeito travesti, explicitando que, segundo Foucault (2018), por meio da prática 
confessional, o sujeito estabelece relações com essa verdade e, também, de dependência com o outro, modificando a relação que tem consigo, num cuidado de si:

1) Não quero que me vejam como um pedaço de carne. Não quero ser assediada o tempo inteiro, mas também não quero ser vista como uma pessoa que vai dar uma facada ou roubar quem quer que seja. Essas são as narrativas que são atreladas a ideia da travesti. ${ }^{8}$

2) Prefiro por uma questão política, de quebra. Eu poderia usar um termo mais leve, mas não é por aí. A ideia é 'positivar'. As pessoas têm orgulho de ser travesti. Por uma questão política, me afirmo como travesti. ${ }^{9}$

Esses dois últimos enunciados apresentam a relação da travesti com o outro, com o social, e, também, explicitam como essa relação com o outro corrobora para a construção de um cuidado de si. Conforme Foucault (2004, p. 4), “cuidar de si é se munir dessas verdades: nesse caso, a ética se liga ao jogo da verdade.”. Assim, nesses enunciados, observamos como a ética, a conduta de si, é confessada, como em: 1) não quero que me vejam como um pedaço de carne e em 2) Por uma questão política, me afirmo como travesti. Analisamos esses enunciados sob a ótica da confissão amparados em Foucault (2018, p.7), para quem, o ato de confessar-se "implica que quem fala se compromete a ser aquilo que afirma ser, e precisamente porque é aquilo.".

Quando mobilizamos os discursos de confissão e a transgressão como instrumentos teórico-analíticos, observamos ainda que a travesti rompe com o estigma de marginalização e enuncia o seu posicionamento político frente a essa exclusão, como mencionado anteriormente, rompendo com o padrão cisheteronormativo, que evoca toda uma memória discursiva de violência sobre o comportamento da travesti, marginalizando-a por sua sexualidade e por atos de violência relacionados a esse sujeito, como expresso no enunciado 1.

Acerca da constituição identitária da travesti, portanto, analisamos que a transgressão é um dos modos de se operar esse processo, funcionando como um solo de possibilidade para essa subjetividade. De modo análogo à loucura, ao pensarmos no corpo social que foge à norma, observamos que o louco se constitui como tal no jogo de verdade e nas "formas de reconhecimento de si mesmo em relação à norma da loucura: reconhecida a norma, subjetiva-se o louco.”. (PRADO FILHO, 2005, p. 49). Assim, com relação à travesti, enquanto sujeito que transgride pela sexualidade, ela se reconhece a si mesma por meio

\footnotetext{
8 https://glo.bo/2EdnAlM

9 https://glo.bo/1y7Jfqx
} 
da confissão, de enunciar a verdade de si e, também, por um dispositivo de sexualidade cisheteronormativo, que normatiza e normaliza as condutas sexuais na sociedade.

\section{A EDUCAÇÃO E O CUIDADO DE SI: A TRANSGRESSÃO COMO CAMINHO PARA AS PRÁTICAS LIBERDADE}

No prosseguimento da discussão sobre o cuidado de si da travesti e como, por essa prática no campo educacional, esse sujeito exerce práticas de liberdade, discutimos, neste momento, sobre como a educação se mostra como um caminho para um exercício do que Foucault (2004) explicita como um gnôthi seauton. Essa prática, explica o autor, refere-se a como o sujeito, para praticar a liberdade tem a necessidade de ocupar-se de si, bem como cuidar de si.

Para essa discussão, comungamos, também, além dos estudos de Michel Foucault, do referencial teórico da Linguística Aplicada Transgressiva para pensarmos a transgressão da travesti no espaço institucional da universidade porque, como argumenta Pennycook (2006, p. 75) “a teoria da transgressão não só desafia os limites e os mecanismos que sustentam as categorias e os modos de pensar, mas também produz outros modos de pensar.". Analisamos o corpo e a sexualidade da travesti como transgressão na universidade tendo em vista que a ocupação desse espaço institucional por esse sujeito marginalizado, com pouco acesso à educação e, consequentemente, ao mercado de trabalho formal, o que reforça a necessidade de readequação desse espaço.

Portanto, para adentrarmos a essa discussão, apresentamos a primeira série enunciativa deste tópico:

1) Eu me sentia como se o conhecimento acadêmico fosse próprio de pessoas brancas e heterossexuais. E a minha presença era quase uma maculação do espaço acadêmico. ${ }^{10}$

2) Nós vivemos numa posição que a sociedade nos impõe, à margem de tudo. E temos que quebrar esse paradigma e viver no centro da sociedade, a educação é uma das formas que temos para conseguir. ${ }^{11}$

3) A história da minha vida quer dizer isso: 'É possível'. É possível ser travesti e ser professora, é possível ser travesti e ser doutora, é possível ser travesti e ser gestora e agora é possível até ser reitora, um espaço em que jamais se pensou. ${ }^{12}$

\footnotetext{
10 https://glo.bo/2HMdMpf

11 https://glo.bo/2Wxel3X

12 https://glo.bo/1y7Jfqx
} 
Nos enunciados em análise, observamos como a ocupação da universidade pela travesti rompe barreiras, transgride e abre caminhos, indicam possibilidades, para que outras travestis possam ocupar, resistir e existir nesses espaços. No que diz respeito às transgressões, embasados em Pennycook (2006), para quem a educação deve servir para transgredir, compreendemos que o acesso ao ensino age como solo para os questionamentos acerca daquilo que é concebido como norma, tanto na universidade quanto na sociedade. Assim, em 1 o sujeito travesti enuncia que sua presença era "maculação" da academia. Em 2, há a enunciação de que a educação é um dos modos de "quebrar esse paradigma e viver no centro da sociedade" e, em 3, o sujeito enuncia que "É possível ser travesti e ser professora, é possível ser travesti e ser doutora".

Analisamos, nesses enunciados, que o sujeito travesti, pela educação, no exercício de um cuidado de si, pode ocupar uma posição-sujeito detentora de um saberpoder conferida pelo grau acadêmico de doutorado: a travesti doutora. A esse respeito, explica Foucault (2004, p. 5) que:

o cuidado de si permite ocupar na cidade, na comunidade ou nas relações interindividuais o lugar conveniente - seja para exercer uma magistratura ou para manter relações de amizade. Além disso, o cuidado de si implica também a relação com um outro, uma vez que, para cuidar bem de si, é preciso ouvir as lições de um mestre

Dito isso, nos enunciados nesta primeira série, referem-se ao cuidado de si confessado pela formação acadêmica e como, por esse cuidado de si, no movimento de transgredir e ocupar a universidade, mais especificamente, um programa de pósgraduação em nível de doutorado, esse sujeito travesti, na relação com o outro, resiste aos imperativos de um discurso de cisheteronormatividade e exerce práticas de liberdade, pois "a luta para se tornar autor do seu próprio mundo, de ser capaz de criar os seus próprios significados, buscar por alternativas culturais em meio à cultura política da vida cotidiana (PENNYCOOK, 1997, p. 39)”.

No escopo da LA Transgressiva, partilhamos do pensamento de Pennycook (2006) para quem uma educação transgressora reside no domínio de combater, afrontar e romper os limites da dominação, seja por questões raciais, de gênero ou de classe. Na continuidade das análises, observemos os seguintes recortes dos enunciados apresentados anteriormente: Em 1, "Eu me sentia como se o conhecimento acadêmico fosse próprio de pessoas brancas e heterossexuais". Em 2, "a educação é uma das formas que temos para conseguir" e, em 3, o sujeito enuncia que "e agora é possível até 
ser reitora, um espaço em que jamais se pensou.”. Nesses enunciados, analisamos, então, como o dispositivo de cisheteronormatividade funciona como um mecanismo de exclusão da travesti e, por outro lado, como a educação é uma das estratégias adotadas por esse sujeito contra esse imperativo e, no exercício do cuidado de si pela educação, o título de doutora instaura um acontecimento discursivo: a possibilidade de ser reitora da universidade em que leciona.

Como defende Urzêda-Freitas (2012, p. 2), em tradução de Hooks (1994):

Com todas as suas limitações, a sala de aula continua sendo um lugar de possibilidades. E, nesse campo de possibilidades, nós [professores/as] temos a chance de trabalhar pela liberdade, de exigir de nós mesmos/as e de nossos/as colegas uma abertura de espírito e de coração que nos permita encarar a realidade, imaginando, coletivamente, caminhos para nos mover além das fronteiras, para transgredir.

Observamos nos enunciados em análise que o funcionamento do cuidado de si pelas práticas da educação é um modo de resistência que abre caminhos para que outras travestis possam ocupar também a universidade e, posteriormente, os programas de pós-graduação no Brasil. Assim, amparados em Foucault (2004), analisamos que esse cuidado de si, ainda que não alcance fisicamente todas as travestis e pessoas trans no país, é um modo de se alcançar a visibilidade desses corpos que a luz não toca, como disserta Foucault em "A vida dos homens infames". Para o autor, o cuidado de si "poderá ser, ao mesmo tempo, senão um cuidado dos outros, pelo menos um cuidado de si benéfico para os outros." (FOUCAULT, 2004, p. 6).

Apresentamos, então, nossa segunda série enunciativa deste tópico, a qual trata da importância da ocupação dos espaços e de um cuidado de si que alcança o outro:

1) Quando esses alunos estão aprendendo a me ver como alguém capaz de ensinálos, eles aprendem a ver outras narrativas sobre nós. Quando estão acostumados a imaginar que o único lugar que a gente pode habitar são as esquinas mal iluminadas das cidades, e começam a me ver na sala de aula, percebem que tem muita coisa a aprender comigo. ${ }^{13}$

2) Para mim, é uma felicidade ser a primeira nas coisas, mas também uma tristeza. Se eu sou a primeira, isso quer dizer que quantas pessoas não estão conseguindo chegar a esses espaços por causa de preconceito? Quantos não estão desistindo da escola por serem hostilizados? ${ }^{14}$

Interpretamos, então, esses enunciados na perspectiva de um cuidado de si e do outro (primeiro recorte), intermediado pela prática docente, que possibilita aos alunos

\footnotetext{
13 https://glo.bo/2EdnAlM

14 https://glo.bo/1y7Jfqx
} 
uma outra perspectiva sobre o sujeito travesti: Quando esses alunos estão aprendendo a me ver como alguém capaz de ensiná-los, eles aprendem a ver outras narrativas sobre nós. Já em 2, o cuidado de si tangencia o outro marginalizado: Se eu sou a primeira, isso quer dizer que quantas pessoas não estão conseguindo chegar a esses espaços por causa de preconceito?

Em uma perspectiva foucaultiana, acerca do primeiro enunciado, lemos tal materialidade sob a ótica da obra A Ordem do Discurso, porque, como teoriza Foucault (2008, p. 36), "ninguém entrará na ordem do discurso se não satisfizer a certas exigências ou se não for, de início, qualificado para fazê-lo.” Tal qual como o sujeito que correspondeu às coerções e aos procedimentos internos e externos de controle dos discursos e pôde ocupar a posição-sujeito de: professora doutora. Pelo viés da Linguística Aplicada Transgressiva, constatamos o ato de uma travesti lecionar também como uma transgressão e esse ato funcionar como uma educação para a transgressão, como defende Pennycook (2006, p. 76)

A LA Transgressiva vai, portanto, além dos limites normativos, procura imaginar de forma diferente, mantendo tanto a ação política do ensinar para transgredir de Hooks como também as questões de ensino imbricadas no ensino como transgressão, tanto Fanon como Foucault

Analisamos, então, que o sujeito travesti que fala nesses enunciados, por meio do cuidado de si, exerce o que Foucault (2004, p. 9) conceitua como preceitos para um bom governante: "o cuidado de si aparece como condição pedagógica, ética e também ontológica para a constituição do bom governante. Constituir-se como sujeito que governa implica que se tenha se constituído como sujeito que cuida de si.”.

Portanto, refletindo sobre como o cuidado de si no âmbito da educação funciona discursivamente, identificamos que a transgressão, tanto em perspectiva foucaultiana quanto na Linguística Aplicada Transgressiva, age, assim como na constituição identitária, de modo a possibilitar o governo de si e do outro para as práticas de liberdade, uma vez que há a emancipação da travesti como sujeito autônomo, livre, porque a liberdade é política e essa liberdade diz respeito a não ser escravo de si e dos outros, como discute Foucault (2004, p. 5), "no caso do homem livrem acredito que o postulado de toda essa moral era que aquele que cuidasse adequadamente de si mesmo era, por isso mesmo, capaz de se conduzir adequadamente em relação aos outros e para os outros.”. 
REVISTA X, Curitiba, volume 14, n.4,p. 120-134, 2019

\section{O CUIDADO DE SI E AS PRÁTICAS DE LIBERDADE: ACONTECIMENTOS TRANSGRESSORES}

Após termos tratado nos tópicos anteriores acerca do cuidado de si e das relações estabelecidas entre a confissão e a constituição identitária da travesti e da educação como cuidado de si, sendo esses perpassados pela transgressão, discutimos, agora, sobre como essas transgressões funcionam como acontecimentos discursivos que instauram e possibilitam práticas de liberdade para esse sujeito. Pensamos na transgressão como um acontecimento tendo em vista os enunciados produzidos por tal funcionamento do discurso porque há a ocorrência de uma ruptura no discurso. A esse respeito, Silva Júnior (2018, p. 20) explica que essa ruptura é:

passível de análise e descrição de uma certa regularidade de seus princípios constitutivos, assim como o procedimento de sua análise configura-se como um diagnóstico do presente, posto que nosso olhar volta-se para a contemporaneidade, no sentido de compreender a singularidade do funcionamento da transgressão.

A série enunciativa recortada para essa última seção trata dessas transgressões, as quais, para nós, produzem efeitos de sentido de acontecimentalização

1) Da mesma maneira que é importante ter a primeira presidenta do Brasil, também é simbólico ter uma primeira travesti a assumir esses espaços. É uma forma de empoderamento de sujeitos que são historicamente marginalizados. ${ }^{15}$

2) Eu fico muito emocionada porque é difícil colocar o adjetivo de doutora, um título de doutora, antes do meu nome. Eu ainda estou absorvendo isso. Porque parecia que era uma história que não era minha porque depois de tudo que eu enfrentei nessa vida, vivenciar um momento tão potente de uma aceitação tão grande, de uma felicidade tão grande, parecia que nem era comigo. ${ }^{16}$

3) A Universidade aprendeu a se transformar para que pessoas como eu caibam ali. $^{17}$

4) A gente vai comemorar cada uma dessas vitórias, mas deixar claro que não vamos nos contentar com elas. ${ }^{18}$

A partir desses enunciados, observamos o caráter de acontecimento discursivo possibilitado pelo caráter transgressivo que fomenta esses movimentos e materializa-se no corpo da travesti, seja pela ocupação do espaço, como em 1. Pelo mecanismo

\footnotetext{
15 https://glo.bo/1y7Jfqx

16 https://glo.bo/2HMdMpf

17 https://glo.bo/2EdnAlM

18 https://glo.bo/2EdnAlM
} 
linguístico da adjetivação em 2 , ao obter o título de doutora, o que a objetiva e a subjetiva. Pela mudança na Instituição para que esse corpo, esse sujeito, a travesti possa ocupar esse espaço, como em 3 e, por fim, o quarto enunciado que expressa o movimento de resistência contínuo aos movimentos de exclusão desse corpo, desse sujeito, da travesti, para que outros tantos acontecimentos possam vir a ocorrer.

A respeito do corpo da travesti e na esteira da discussão sobre o acontecimento, o corpo está em um regime de visibilidade e de consequente produção discursiva, sendo que o papel do analista de discurso é, como Milanez (2011, p. 199) expõe: olhar para o corpo no que ele tem de materialidade e de acontecimento. [..], apontando deslocamentos, descrevendo materialidades nas quais encontramos singularidades e coerções dos sujeitos, compreendendo-os em sua materialidade e produção discursiva.

Assim, ao analisarmos esses enunciados como acontecimentos transgressores e instauradores de práticas de liberdade, observamos que o cuidado de si pela educação é um dos elementos que dá a esses discursos as condições de possibilidade necessárias pelo funcionamento de uma ética de si, porque, como indaga Foucault (2004, p. 3): “o que é a ética senão a prática da liberdade, a prática refletida da liberdade?"

Interpretamos essa última série enunciativa, portanto, sob a ótica de um cuidado de si no interior das relações de poder, as quais, conforme a movência dessas relações, elas possibilitam, desse modo, o exercício de práticas de liberdade em meio aos jogos de poder, uma vez que a própria descontinuidade na história é motor para esse funcionamento.

Sobre os jogos de poder e as práticas de liberdade, observamos como o dispositivo cisheternormativo funciona de modo a marginalizar a travesti e esse sujeito travesti o transgride, como no enunciado 1, considerando que nesses jogos "uns tentem determinar as condutas dos outros, ao que os outros tentam responder não deixando sua conduta ser determinada ou determinando em troca a conduta dos outros - e os estados de dominação, o que geralmente se chama de poder.”. (FOUCAULT, 2004, p. 13)

$\mathrm{Na}$ esteira desse pensamento sobre as práticas de liberdade do corpo da travesti, observamos que a resistência e os deslocamentos que ela provoca na dinâmica do exercício do poder, segundo o funcionamento dos diagramas desse, residem no domínio daquilo que está relacionado à atitude crítica do sujeito, na transformação de si e do outro, e nas alianças como políticas de coalização. Conforme teoriza Duarte (2017, p. 153), em consonância com Butler: 
tal política de coalizão não pretenderia estabelecer um consenso primeiro ou definitivo em torno do significado ou da verdade de cada sujeito (homem, mulher, gay, lésbica, trans, intersex, negro/a, indígena etc.), tampouco teria como meta alcançar tal consenso ou unidade, mas se organizaria no curso de lutas comuns, capazes de associar e identificar agentes políticos distintos, preservando, contudo, suas diferenças e distinções.

Por fim, retomamos o último enunciado, em que o sujeito diz que cada vitória será comemorada e que não se contentará com as vitórias já alcançadas. No escopo da discussão sobre as práticas de liberdade, analisamos esse último enunciado como um fechamento, por ora, da discussão aqui proposta, procurando explicitar como esse enunciado produz um efeito de sentido de resistência no jogo das relações de poder.

Ainda que o sujeito travesti tenha alcançado esse lugar, o grau mais alto de uma titulação acadêmica, esse cuidado de si implica no cuidado do outro também, sendo esse outro outras tantas travestis e pessoas transexuais que não ocupam essa instituição que lhes é de direito: a universidade, porque, para Foucault $(2004$, p. 8) "se há relações de poder em todo o campo social, é porque há liberdade por todo lado.”. Assim, se há liberdade, se há liberdade para ser o que se é, que as travestis continuem a resistir e a ocupar outros tantos espaços em nossa sociedade.

\section{CONCLUSÃO}

Os depoimentos das travestis doutoras, expostas neste artigo, apontam para a dificuldade que esses sujeitos e esses corpos enfrentam no espaço social brasileiro na contemporaneidade, cujo alto índice de violência recai sobre a comunidade LGBT+. Apesar disso, esses sujeitos resistem e conseguem adentrar o espaço acadêmico, seja na condição estudante ou na de profissionais que passam a exercer a docência, construindo outras imagens sobre esses corpos, majoritariamente, vistos como profissionais do sexo ou como corpos a serem eliminados do espaço social, seja por meio da violência simbólica ou pelos crimes cometidos contra esses sujeitos.

Os depoimentos das travestis, conforme casos aqui estudados, são acontecimentos singulares e ainda raros, pois a grande maioria não conseguiu adentrar o espaço escolar em nem o da academia. São sujeitos que transgridem não apenas a sexualidade padronizada, mas o próprio espaço social, pois são corpos e identidades que desafiam o modelo binário da sexualidade. Ao relatar as dificuldades enfrentadas, seja no meio familiar, escolar ou social, essas travestis resistem, existem e se posicionam frente aos discursos normalizadores e normatizadores da sociedade, sobretudo no campo educacional. Aliás, o espaço educacional 
configura-se como um limite paradoxal, pois atua tanto como um lugar de discriminação, se pensarmos na dificuldades das travestis de terem acesso a formação escolar, quanto de emancipação, na medida em que possibilita novos olhares a esses sujeitos, principalmente, nos casos aqui indicados.

Esse trabalho de construção subjetiva, que passa pelo cuidado de si, faz com esses sujeitos construam seus espaços de liberdade sem se deixarem dominar pelos discursos normalizadores correntes. É pelo cuidado de si que se emancipa, libertando-se, e emancipandose esses sujeitos continuam a resistir, sem se colocarem na condição de escravo dos outros.

\section{REFERÊNCIAS}

DUARTE, A. M.. Reler Foucault à luz de Butler: repensar a biopolítica e o dispositivo da sexualidade. DOIS PONTOS (UFPR) DIGITAL, v. 14, p. 253-264, 2017.

FOUCAULT, Michel. A ética do cuidado de si como prática da liberdade. In: Ditos \& Escritos V - Ética, Sexualidade, Política. Rio de Janeiro: Forense Universitária, 2004. Disponível em:

http://escolanomade.org/wpcontent/downloads/foucault_\%20etica_cuidado_si.pdf Acesso em 04 de novembro de 2018.

É inútil revoltar-se? [1979]. In: MOTTA, Manoel Barros da (Org.). Michel Foucault. Ditos e Escritos: Ética, sexualidade e política. v. V. Tradução Elisa Monteiro e Inês Autran Dourado Barbosa. 2.ed. Rio de Janeiro: Forense Universitária, 2006. p. 77-81. (Coleção Ditos e Escritos).

A Ordem do Discurso. Trad. Laura Fraga de Almeida Sampaio. 18. ed. São Paulo: Edições Loyola, 2008.

. Os Anormais: curso no Collège de France. Trad. Eduardo Brandão - São Paulo:

WMF - Martins 2010.

. Entrevista com Michel Foucault. In.: Ditos e escritos Vol. I: problematização do sujeito: psicologia, psiquiatria e psicanálise. 3. ed. Rio de Janeiro: Forense, 2014.

Malfazer, dizer verdadeiro. Função da confissão em juízo - curso em Louvain, 1981. 1ªed. São Paulo: Martins Fontes, 2018.

HOOKS, B. Teaching to transgress: education as the practice of freedom. New York: Routledge, 1994.

MILANEZ, N. Materialidades da paixão: sentidos do olhar para uma semiologia do corpo. In: SARGENTINI, V; PIOVEZANI, C.; CURCINO, L. (Org.). Discurso, semiologia e história. 1. ed. São Carlos: Claraluz, 2011.

PENNYCOOK. A. Cultural Alternatives and Autonomy. (pp. 35-53)In: Benson, P \& Voller, P. Eds.. Autonomy \& Independence in language learning. London and New York: Longman, 1997. 
Uma Linguística Aplicada Transgressiva. IN: MOITA-LOPES, L.P. [Org]. Por uma Linguística Aplicada Indisciplinar. São Paulo: Parábola Editorial, 2006.

PRADO FILHO, K. Uma História Crítica da Subjetividade no pensamento de Michel Foucault. In: Falcão, L. F.; Souza, P. (Org.). Michel Foucault: Perspectivas. Rio de Janeiro: Achiamé, 2005, p. 41 - 50.

SILVA JÚNIOR, W. D. da. A transgressão nos estudos do discurso [manuscrito]: caminhos para uma operacionalização conceitual. Tese de Doutorado, Programa de Pós-Graduação em Letras e Linguística, UFG, 2018.

URZÊDA-FREITAS, M. T.. "Educando para transgredir": reflexões sobre o ensino crítico de línguas estrangeiras/inglês. Trabalhos em Linguística Aplicada (UNICAMP), v. 51, p. 77-97, 2012. 